\title{
The Production and Physicochemical Properties of a Biosurfactant Mixture Obtained from Sphingobacterium detergens
}

\author{
Burgos-Díaz $C^{1}$., Pons $\mathrm{R}^{2}$., Teruel J.A ${ }^{3}$., Aranda F.J. ${ }^{3}$, Ortiz A ${ }^{3}$., Manresa \\ $\mathrm{A}^{1}$., Marqués A. $\mathrm{M}^{1 *}$. \\ ${ }^{1}$ Laboratory of Microbiology, Fac. of Pharmacy, Univ. Barcelona, Av. Joan XXIII, 08028 Barcelona, Spain. \\ ${ }^{2}$ Dept. de Tecnologia Química i de Tensioactius, Institut de Química Avaçada de Catalunya, IQAC-CSIC, Jordi \\ Girona 18-26, 08034 Barcelona, Spain \\ ${ }^{3}$ Dept. of Biochemistry and Molecular Biology-A, Veterinary Fac., Univ Murcia, 30100 Murcia, Spain. \\ * Corresponding author. Fax: +34934024498. E-mail address: ammarques@ub.edu (A.M. Marqués)
}

\begin{abstract}
The commercial application of a new biosurfactant such as the one produced by Sphingobacteriun detergens needs a cost-effective process and knowledge of its properties. In the present study, a specific medium and a downstream process have been developed to enhance biosurfactant production. Optimal concentrations of nutrients in MCA medium were (g/L): $\mathrm{KH}_{2} \mathrm{PO}_{4}, 1 ; \mathrm{K}_{2} \mathrm{HPO}_{4}, 2 ; \mathrm{CO}\left(\mathrm{NH}_{2}\right)_{2} \quad 0.88 ; \mathrm{CaCl}_{2}$ 0.01; $\mathrm{FeSO}_{4} \cdot 7 \mathrm{H}_{2} \mathrm{O}, 0.01 ; \mathrm{MgSO}_{4} \cdot 7 \mathrm{H}_{2} \mathrm{O} 0.5 ; \mathrm{KCl}, 1.0$; trace elements $0.05 \mathrm{~mL}$. Biosurfactant production in the MCA medium required a bacterial co-metabolism of glucose and an $n$ alkane. A fed-batch culture with supernatant lyophilization prior to organic extraction produced $466 \mathrm{mg} / \mathrm{L}$ of organic extract, which represents a 6.9-fold increase in production. The newly obtained biosurfactant was a complex mixture of molecules. The three characterized fractions consisted of the complete fraction and two second-level purification fractions with apolar and polar characteristics. The complete and apolar fractions have been shown to self-aggregate in the form of lamellar liquid crystals at a high concentration and bilayers at lower concentrations. Negatively charged particles were identified, which were neutralized at a low $\mathrm{pH}$ with a concomitant increase in size. The $\mathrm{pH}$ affected the surface tension of the solutions congruently with phosphate headgroups.
\end{abstract}

Keywords: Biosurfactant, Sphingobacterium detergens, co-metabolism, CMC, X-ray Scattering, $\zeta$-potential, lamellar phases.

\section{1.-Introduction}

It is becoming increasingly apparent that understanding microbial behavior necessarily involves a better understanding of biosurfactant (BS) activity at interfaces, since microbial activity takes place on boundaries. BS dramatically influences microbial physiological behavior in areas such as cell mobility, cell communication, nutrient accession, cell-cell competition and plant and animal pathogenesis [1]. Bushnell and Hass [2] were among the first to demonstrate bacterial production of biosurfactants (BS) by isolating Corynebacterium simplex and a strain of Pseudomonas in mineral media containing either kerosene, mineral oil or paraffin. Since then, many microorganisms have been isolated and found to produce a variety of BS molecules [3]. Microbial surfactants constitute a diverse group of molecules and are known to occur in chemical structures, such as glycolipids, lipopeptides and lipoproteins, fatty acids, neutral lipids, phospholipids and polymeric and particulate structures [4]. 
Surfactants are one of the most representative chemical products and are consumed in large quantities every day on a worldwide scale. Many traditional surfactants exhibit an insufficient rate of biodegradation and high aquatic toxicity [5]. In comparison, in recent years, BS have attracted considerable scientific attention due to their high surface activity, reduced toxicity, easy biodegradability, better environmental compatibility, higher foaming and higher selectivity. These interesting properties, and BS effectiveness at extreme temperature, salinity and $\mathrm{pH}$, and their ability to be synthesized from renewable feedstocks, have led to a growing interest in BS as an alternative to compounds obtained by chemical synthesis [6-9].

Research in BS has expanded in recent years due to their potential use in different industrial areas (food, agriculture, paper, and metal or hydrocarbon remediation) or in the biomedical field (antimicrobial, antifungal, antioxidant, antiviral or cytotoxic activity), leading to high added value products. Nonetheless, in order to gain a significant share of the market, BS must be produced at a lower cost [10].

The growing demand for green products has also been the driving force for new BS development in the last few years. Despite the advantages and diverse potential applications of BS, attempts at commercial production have been unsuccessful due to the low yields obtained [11-12]. Under certain growth conditions, some microorganisms can increase BS production, which is influenced by the effect of various chemical and physical factors and media composition [13]. A new BS producer, Sphingobacterium detergens strain $6.2 \mathrm{~S}$, has been recently described [14]. This bacteria produces a mixture of compounds initially classified as phospholipids, glycolipids and lipopeptides. The crude extract and purified polar fraction produced by $S$. detergens are able to reduce the surface tension of water to very low values (22 and $23 \mathrm{mN} \mathrm{m}^{-1}$, respectively) due to synergism [14]. The presence of nitrogen in the polar fraction in the absence of amino acids suggests the presence of a new BS, whose high effectiveness and possible new structure make it a very interesting target of study. However, complete and precise characterisation of this kind of compounds is difficult due to the low availability of samples. Large-scale production of these molecules is hampered by the low yields of production processes and to the intrinsic complexity of separation due to the similarity of products present in the crude extracts.

The present work reports the first steps to improve $S$. detergens production of BS and their preliminary physicochemical characterization. With this aim, the concentration of the different components of the culture medium were optimized. As a second strategy, the $\mathrm{pH}$ and limiting nutrients were controlled during bacterial growth in order to extend the production period. The raw BS were separated in two different polarity fractions, corresponding to chemical mixtures. Both fractions, as well as the complete extract, were characterized in terms of particle size and charge as a function of $\mathrm{pH}$. Further, the particles were studied using small angle x-ray scattering (SAXS). The surface tension as a function of salinity and $\mathrm{pH}$ was highly dependent on the studied fraction. The results are discussed in terms of the composition of the different fractions and charged headgroups. 


\section{Materials and methods}

\subsection{Microorganism and culture conditions for BS production}

Strain 6.2S was isolated from non-contaminated soil and characterized as Sphingobacteriun detergens [15]. This strain was maintained by fortnightly subculture on Trypticese Soy Agar (Pronadisa, Spain) and preserved in cryovials at $-20^{\circ} \mathrm{C}$ (Combourg, France).

For BS production, the mineral salt medium (S-MSM) of the following composition was used (g/L): $\mathrm{KH}_{2} \mathrm{PO}_{4}, 0.5 ; \mathrm{K}_{2} \mathrm{HPO}_{4}, 1 ; \mathrm{NaNO}_{3}, 1.2 ;\left(\mathrm{NH}_{4}\right)_{2} \mathrm{HPO}_{4}, 1.1 ; \mathrm{CaCl}_{2} 0.01$; FeSO4. $7 \mathrm{H}_{2} \mathrm{O}, 0.01 ; \mathrm{MgSO}_{4} \cdot 7 \mathrm{H}_{2} \mathrm{O} 0.5 ; \mathrm{KCl}, 1.0$; yeast extract, 0.05 ; trace element solution, $0.05 \mathrm{~mL}$. Carbon source $0.05 \mathrm{C}_{11-13}\left(\mathrm{C}_{10} 9.3 \%, \mathrm{C}_{11} 32.4 \%, \mathrm{C}_{12} 31.3 \%, \mathrm{C}_{13}\right.$ $26.7 \%$ ) and 0.05 sodium citrate plus $2 \%(\mathrm{~V} / \mathrm{V})$ of inoculum suspension in Ringer solution was added. To avoid complex formation, the mineral media and the carbon sources were autoclaved separately [14]. Cultures were incubated at $30^{\circ} \mathrm{C}$ in a $1000 \mathrm{~mL}$ baffled Erlenmeyer flask with $200 \mathrm{~mL}$ basal medium for $48 \mathrm{~h}$ with agitation at $150 \mathrm{rpm}$.

\section{$2.2 B S$ recovery}

Broth samples were collected and checked for bacterial growth (measured as protein by the Lowry method, Bio-Rad $\mathrm{D}_{\mathrm{c}}$ Protein assay), $\mathrm{pH}$, and surface and interface tension. The organic extract was recovered from the culture supernatant after cell removal by centrifugation at $8000 \times \mathrm{x}$ for $15 \mathrm{~min}$ in an Avanti $^{\mathrm{TM}} \mathrm{j}-20 \mathrm{xp}$ centrifuge (Bekman Coulter ${ }^{\mathrm{TM}}$, USA) for $15 \mathrm{~min}$ at $4^{\circ} \mathrm{C}$. The supernantant was extracted three times with an equal volume of an ethylacetate-methanol mixture $(8: 1, \mathrm{~V} / \mathrm{V})$. Organic phases were combined, dried over anhydrous sodium sulphate and concentrated to dryness in a rotary vacuum evaporator (Büchi, Switzerland). The resulting organic extract was weighed.

\subsection{Effect of nutrients on Biosurfactant Production}

$S$. detergens was grown aerobically in $250 \mathrm{~mL}$ S-MSM medium in $1000 \mathrm{~mL}$ baffled Erlenmeyer flasks, supplemented with $2 \% \mathrm{C}_{11-13}$. The entire content of three sets of flasks was sacrificed periodically for surface and interfacial tension, biomass and BS quantification. The following nitrogen sources were evaluated for $\mathrm{BS}$ production: $\mathrm{NaNO}_{3},\left(\mathrm{NH}_{4}\right)_{2} \mathrm{HPO}_{4},\left(\mathrm{NH}_{4}\right)_{2} \mathrm{SO}_{4}$ and $\mathrm{CO}\left(\mathrm{NH}_{2}\right)_{2}(0.44-1.32 \mathrm{~g} / \mathrm{L})$. The most appropriate concentrations of $\mathrm{FeSO}_{4} \cdot 7 \mathrm{H}_{2} \mathrm{O}, \mathrm{KH}_{2} \mathrm{PO}_{4} / \mathrm{K}_{2} \mathrm{HPO}_{4}, \mathrm{MgSO}_{4}, \mathrm{KCl}$ and $\mathrm{CaCl}_{2}$ were studied in a range of $2.5-15 \mathrm{mg} / \mathrm{L} ; 1 / 0.5-4 / 2 \mathrm{~g} / \mathrm{L} ; 0.1-0.2 \mathrm{~g} / \mathrm{L} ; 0.5-1.5 \mathrm{~g} / \mathrm{L}$ and $5-15 \mathrm{mg} / \mathrm{L}$, respectively. Glycerol, olive oil, kerosene, $\mathrm{C}_{11-13}, \mathrm{C}_{13}, \mathrm{C}_{12-14}, \mathrm{C}_{15}$ were employed as the carbon source as indicated.

\subsection{Time course of growth}

A modified MCA medium with the following composition was used (g/L): $\mathrm{KH}_{2} \mathrm{PO}_{4}, 1$; $\mathrm{K}_{2} \mathrm{PO}_{4}, 2 ; \mathrm{CO}\left(\mathrm{NH}_{2}\right)_{2} 0.88 ; \mathrm{CaCl}_{2} 0.01 ; \mathrm{FeSO} 4 \cdot 7 \mathrm{H}_{2} \mathrm{O}, 0.01 ; \mathrm{MgSO}_{4} \cdot 7 \mathrm{H}_{2} \mathrm{O} 0.5 ; \mathrm{KCl}$, $1.0 ;$; trace element solution, $0.05 \mathrm{~mL}$. Carbon source $1.5 \%(\mathrm{~V} / \mathrm{V}) \mathrm{C}_{11-13}\left(\mathrm{C}_{10} 9.3 \%, \mathrm{C}_{11}\right.$ $\left.32.4 \%, \mathrm{C}_{12} 31.3 \%, \mathrm{C}_{13} 26.7 \%\right)$ and glucose $(20 \mathrm{~g} / \mathrm{L})$ plus $2 \%(\mathrm{~V} / \mathrm{V})$ of inoculum suspension in Ringer solution were added. To avoid complex formation, the mineral media and the carbon sources were autoclaved separately. Cultures were incubated at 
$30^{\circ} \mathrm{C}$ for $24-48 \mathrm{~h}$ at $150 \mathrm{rpm}$. During culture growth, broth samples were collected at regular time intervals. Growth was monitored by measuring protein. Biosurfactant production was monitored by measuring the surface and interfacial tension against the kerosene $(\mathrm{mN} / \mathrm{m})$ of the supernatant samples. Results represent the mean of triplicate experiments. Measurements of pH were taken using Crison micro pH 2000 (Spain). Consumption of glucose and urea were determined by the Glucose-Test (Microquant ${ }^{\circledR}$, Merck) and Urea Test (Microquant ${ }^{\circledR}$, Merck), respectively. $\mathrm{C}_{11-13}$ consumption was measured in the supernatant by weight at $\mathrm{t}=0$ and after $24 \mathrm{~h}$ culture through three extractions with an equal volume of hexane. Organic phases were combined, dried over anhydrous sodium sulphate and concentrated in a rotary vacuum evaporator (Büchi, Switzerland). Both resulting extracts were weighed and compared. Total viable counts were determined by plate counts on TSA using suitable saline dilutions of the culture in MCA medium. Extract purification was performed according to Burgos-Díaz et al. [14].

\subsection{Study of BS recovery with different organic solvents}

After $48 \mathrm{~h}$ of culture, cells were removed from the medium by centrifugation at $8000 \mathrm{xg}$ for $15 \mathrm{~min}$. BS were recovered from the cell-free concentrate by three extractions with an equal volume of methanol, ether-butyl-ether, ethyl acetate/methanol (8:1), ethyl acetate, chloroform or hexane, and concentrated to dryness. The dry organic extract was weighed. When indicated, the supernatant was first lyophilized (Cryodos-50, Telstar, Spain), concentrated 25 times and extracted as described above.

\subsection{Electronic Microscopy}

Samples were transferred to $1.5 \mathrm{~mm}$ diameter and $200 \mu \mathrm{m}$ depth planchettes, immediately cryoimmobilized using a Leica EMPact high-pressure freezer (Leica, Vienna, Austria) and then stored in liquid nitrogen until further use. They were freezesubstituted over 3 days at $-90^{\circ} \mathrm{C}$ in anhydrous acetone containing $2 \%$ osmium tetroxide and $0.1 \%$ uranyl acetate at $-90{ }^{\circ} \mathrm{C}$ for 72 hours and warmed up to room temperature, $5^{\circ}$ per hour (EM AFS, Leica, Vienna, Austria). After several acetone rinses, samples were infiltrated with Epon resin during 2 days and the resin was polymerized at $60^{\circ} \mathrm{C}$ during 48 hours. Ultrathin sections were obtained using a Leica Ultracut UCT ultramicrotome and mounting on Formvar-coated copper grids. They were stained with $2 \%$ uranyl acetate in water and lead citrate. Sections were then observed in a Jeol 1010 electron microscope (Jeol, Japan)

\subsection{Study of organic extract solubility}

Equal amounts of organic extract (20mg) were dissolved in $1 \mathrm{~mL}$ of different organic solvents with varying polarity (methanol, methyl tertiary-butyl ether, ethyl acetate/methanol (8:1), ethyl acetate, chloroform, hexane) at $25^{\circ} \mathrm{C}$. After vortex mixing for $2 \mathrm{~min}$, and sonication if necessary, the vials were observed against the light.

\subsection{Surface tension measurements}

Equilibrium surface tension $\left(\gamma_{\mathrm{st}}\right)$ was measured at $25^{\circ} \mathrm{C}$ with a Krüss $\mathrm{K} 9$ digital tensiometer (Krüss, GmbH, Hamburg, Germany) using the ring method. The instrument was calibrated against ultrapure water $\left(\gamma_{\mathrm{st}} 72 \mathrm{mN} / \mathrm{m}\right)$ and pure ethanol $\left(\gamma_{\mathrm{st}} 22.7 \mathrm{mN} / \mathrm{m}\right)$ to ensure accuracy over the entire range of surface tension. Prior to use, the platinum ring 
and all glassware were sequentially washed with chromic acid, deionized water, acetone and finally flamed with a Bunsen burner. The effect of ionic strength on critical micelle concentration (CMC) was determined by surface tension measurements using the ring method at $25^{\circ} \mathrm{C}$. Two series of BS solutions were prepared: in $5 \mathrm{mM}$ Hepes (pH 7.0) or in $100 \mathrm{mM}$ sodium citrate (pH 4.0) buffer at $25^{\circ} \mathrm{C}$. Concentrated $\mathrm{NaCl}$ was added to produce five levels (0-300 $\mathrm{mM})$ and the CMC of each BS series was determined.

\section{$2.9 \zeta$-potential and particle size}

A Malvern Zetasizer Nano ZS series HT instrument was used to evaluate both zeta potential and particle size. The dispersions were placed into U-shaped cuvettes equipped with gold electrodes. The temperature was set to $25.0 \pm 0.1{ }^{\circ} \mathrm{C}$. The zeta potential $(\zeta)$ is related to the electrophoretic mobility by Henry's equation. Malvern software was used to analyze the electrophoretic mobility and calculate the corresponding $\zeta$ potential using the Smoluchowski approximation. This was justified due to the large size of the particles and because the screening length was much smaller than the particle radius. The instrument performed additional DLS experiments in back scattering mode at $173^{\circ}$ and $\lambda=632.8 \mathrm{~nm}$. The self-correlation curves were analyzed using the CONTIN routine included in the Malvern control and analysis software. The measurements were run in triplicate and their agreement was within $\pm 5 \%$.

\subsection{Small-Angle X-ray Scattering}

Small-Angle X-ray Scattering (SAXS) measurements were carried out using an S3MICRO (Hecus X-ray systems GMBH Graz, Austria) coupled to a GENIX-Fox 3D Xray source (Xenocs, Grenoble), which provides a focused x-ray beam with a $\lambda=0.1542$

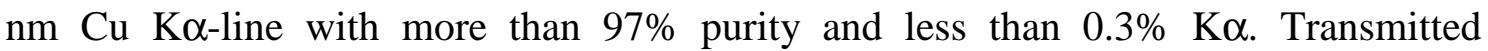
scattering was detected using a PSD 50 Hecus. Temperature was controlled by means of a Peltier TCCS-3 Hecus. Samples were inserted in a glass capillary of $1 \mathrm{~mm}$ diameter and $20 \mu \mathrm{m}$ wall thickness using a flow-through set-up. The SAXS scattering curves are shown as a function of the scattering vector modulus,

$$
q=\frac{4 \pi}{\lambda} \sin \theta / 2
$$

where $\theta$ is the scattering angle. The $q$ values with our set-up ranged from $0.08 \mathrm{~nm}^{-1}$ to $6.0 \mathrm{~nm}^{-1}$. The scattering vector was calibrated by measuring a standard silver behenate sample. Due to the use of a small focused beam ( $300 \times 400 \mu \mathrm{m}$ fwhm), the scattering curves were mainly smeared by the detector width. The scattering curves were background-subtracted and placed on an absolute scale by comparison with a water sample scattering $[16,17]$. The instrumentally smeared experimental SAXS curves were fitted to numerically smeared models for beam size and detector width effects. A least squares routine based on the Levenberg-Marquardt scheme was used. The bilayer model was that of the MCG $[18,19]$.

\subsection{Optical Polarizing Microscopy}


An Olympus BX51 polarized light microscope was used. Images were acquired with an Olympus C-5060 Wide Zoom digital camera. Anisotropic liquid-crystalline phases give rise to typical birefringent textures under polarized light [20]. The magnification of the pictures was assessed against a calibrated scale.

\section{Results and Discussion}

\subsection{Biosurfactant production}

According to Mukherjee et al. [4], the production economy of every microbial metabolite is governed by three basic factors: initial raw material costs; availability of suitable and economic production and recovery procedures; and the product yield of the producer microorganisms. In this work, with the aim of improving the competitiveness of BS production, our strategy was to develop an efficient bioprocess (media and culture conditions) with an effective separation procedure. This improvement was achieved in several steps. BS production in a general medium such as S-MSM gave a low amount of biomass $(0.57 \mathrm{mg}$ protein $/ \mathrm{mL})$ and organic extract $(68 \mathrm{mg} / \mathrm{L})$. In the optimization study the carbon source $\left(\mathrm{C}_{11-13}\right)$ was increased to $20 \mathrm{~g} / \mathrm{L}$, sodium citrate was eliminated and the effect of each component on bacterial growth and BS production was examined.

\subsubsection{Effect of Nitrogen sources on BS production}

The effect of the nitrogen source was the first parameter to be studied. To obtain a defined and equivalent medium, the yeast extract was eliminated and equimolar amounts of other types inorganic nitrogen substrate were supplied. No growth was observed after $48 \mathrm{~h}$ of incubation, indicating that $S$. detergens strain $6.2 \mathrm{~S}$ requires the vitamins or micronutrients in the yeast extract. Results obtained with different nitrogen sources plus $0.1 \%$ yeast extract are shown in Figure 1 . The use of sodium nitrate led to a substantial decrease in surface and interfacial tension $(36.5 \mathrm{mN} / \mathrm{m}$ and $10.4 \mathrm{mN} / \mathrm{m}$, respectively), but cellular growth was limited $(1.6 \mathrm{mg}$ protein $/ \mathrm{mL})$. This behavior can be related to the absence of nitrate reductase in $S$. detergens [15] and the use of the yeast extract as a nitrogen and carbon source. Figure 1 shows that urea $(0.88 \mathrm{~g} / \mathrm{L})$ is more effective than ammonium phosphate and sulfate since a higher protein concentration ( $\mathrm{p}$ value $<0.05$ both) and lower surface and interfacial tension were obtained. Hence, urea was selected as the nitrogen source for all other media combinations.

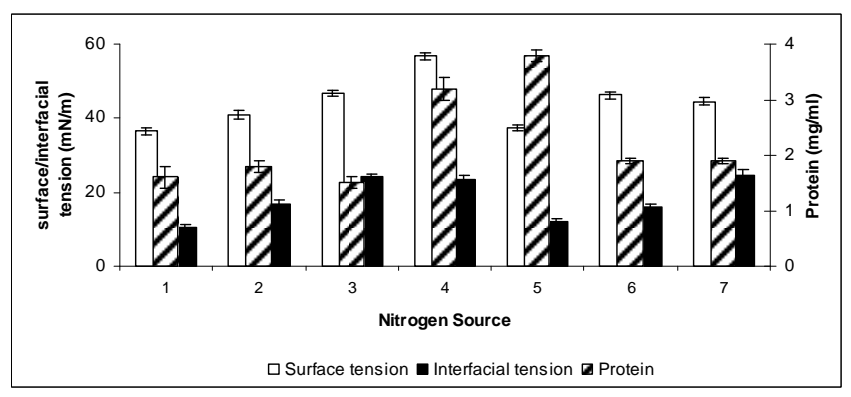

Figure 1: Surface activity in supernatant and biomass (protein) with different nitrogen sources and $0.1 \mathrm{~g} / \mathrm{L}$ yeast extract. Nitrogen sources $(\mathrm{g} / \mathrm{L}) 1: \mathrm{NaNO}_{3}, 2.5$; 2: $\left(\mathrm{NH}_{4}\right)_{2} \mathrm{HPO}_{4}, 1.45 ; 3:\left(\mathrm{NH}_{4}\right)_{2} \mathrm{SO}_{4}, 1.92 ; 4: \mathrm{CO}\left(\mathrm{NH}_{2}\right)_{2}, 0.44 ; 5: \mathrm{CO}\left(\mathrm{NH}_{2}\right)_{2}, 0.88 ; 6$ : $\mathrm{CO}\left(\mathrm{NH}_{2}\right)_{2}, 1.1 ; 7: \mathrm{CO}\left(\mathrm{NH}_{2}\right)_{2}, 1.32$. Error bars indicate \pm standard deviation of three independent experiments. 
The effect of the nitrogen source on BS production depends on the microorganism used. Sodium nitrate proved more effective than ammonium sulfate and urea for obtaining high concentrations of rhamnolipids from $P$. aeruginosa PA1 [10]. Also, the addition of $\mathrm{NaNO}_{3}$ as the sole nitrogen source $(0.1 \%$; w/v) in a glucose-containing MS medium resulted in the highest BS production in $P$. aeruginosa MR01 $(0.98 \mathrm{~g} / \mathrm{L})$. Organic nitrogen sources in the MR01 medium, including yeast extract, urea and peptone, gave a lower BS production [13]. Morita et al. [21] studied the effect of five nitrogen sources on the production of a glycolipid by Ustilago scitaminea. Under optimum conditions, this fungus produced $25.1 \mathrm{~g} / \mathrm{L}$ of MEL-B from sugar cane juice supplemented with urea. BS production by Bacillus circulans was achieved with ammonium sulfate or yeast extract, although the use of urea gave a significantly higher concentration $(1.8 \mathrm{~g} / \mathrm{L})$. Urea is a cheaper chemical than other nitrogen sources and can thus be used as a component in the BS production medium without affecting the process economics [9].

\subsubsection{Effect of the carbon source on BS production: co-metabolism}

When $\mathrm{C}_{11-13}$ was used as the single carbon source, along with urea as the nitrogen source, growth and BS production were only possible with yeast extract $(0.1 \%)$. When another carbon source was used (glucose) with urea, in absence of yeast extract, an abundant growth was observed, indicating that yeast extract is necessary for the growth of strain $6.2 \mathrm{~S}$ in the presence of carbon sources such as the n-alkanes $\mathrm{C}_{11-13}$. Nevertheless, BS production did not occur in these conditions because surface and interfacial tension did not decrease after growth. According to our results (Table 1), BS were produced by strain $6.2 \mathrm{~S}$ only when two carbon sources were present: glucose or yeast extract were used by cells to grow and the $n$-alkane $\left(\mathrm{C}_{11-13}\right)$ was used by cells as an inductor of BS production in a co-metabolism process. A decrease of $76.7 \%$ of $\mathrm{C}_{11}$ 13 during cellular growth was observed after $24 \mathrm{~h}$, indicating its bacterial use as a carbon source or intracellular accumulation. In conclusion, a co-metabolism of glucose plus $\mathrm{C}_{11-13}$ was necessary for BS production by $S$. detergens.

Table 1. Surface measurements and growth of $S$. detergens with different carbon sources after $48 \mathrm{~h}$ culture. Results are expressed as mean \pm standard deviation of three experiments.

\begin{tabular}{ccccc}
\hline Culture conditions & $\begin{array}{c}\text { Surface tension } \\
(\mathrm{mN} / \mathrm{m})\end{array}$ & $\begin{array}{c}\text { Interfacial tension } \\
(\mathrm{mN} / \mathrm{m})\end{array}$ & $\begin{array}{c}\text { Organic extract } \\
(\mathrm{mg} / \mathrm{L})\end{array}$ & $\begin{array}{c}\text { Protein } \\
(\mathrm{mg} / \mathrm{mL})\end{array}$ \\
\hline G-MSM Time 0 h & $55.1 \pm 0.9$ & $32.0 \pm 0.9$ & - & - \\
$\mathrm{G}-\mathrm{MSM}+2 \% \mathrm{C}_{11-13}$ & $45.2 \pm 1.0$ & $24.3 \pm 1.0$ & - & - \\
$\mathrm{G}-\mathrm{MSM}+2 \%$ Glucose & $57.2 \pm 1.1$ & $20.1 \pm 0.8$ & $22.0 \pm 1.2$ & $5.8 \pm 0.5$ \\
G-MSM + & $37.2 \pm 0.8$ & $7.4 \pm 0.7$ & $120 \pm 1.5$ & $3.8 \pm 0.3$ \\
$2 \% \mathrm{C}_{11-13} 2 \%+$ Glucose & $37.2 \pm$ \\
\hline
\end{tabular}

Other authors have described the advantages of using two types of substrates in the culture medium, one miscible and the other immiscible. Van Bogaert et al. [22] and Daverey and Pakshirajan [23] studied the production of sophorolipids by Candida bombicola using a simple medium with a waste carbon source such as sugarcane molasses. They observed that BS production increased several-fold when the production media contained a hydrophilic carbon source supplemented with a lipophilic carbon source. A Pseudomonas species is able to use both water-soluble carbon sources and water-immiscible substrates. Interestingly, when both hydrophilic and hydrophobic substrates were used simultaneously, BS production by Pseudomonas species was found 
to increase significantly [24]. Bento and Gaylarde [25], who studied Pseudomonas sp. and Bacillus sp. isolated from diesel fuel, observed that BS production in the presence of glucose was low, but it rapidly increased on the addition of diesel oil. This result indicates that diesel-oil induced either a higher production, or the production of a chemically different, more effective, emulsifying agent than is synthesized in the presence of glucose alone.

\subsubsection{Effect of other nutrients and phosphate concentration on BS production}

The effect of different concentrations of $\mathrm{FeSO}_{4} \cdot 7 \mathrm{H}_{2} \mathrm{O}, \mathrm{MgSO}_{4}, \mathrm{KCl}$ and $\mathrm{CaCl}_{2}$ on $\mathrm{BS}$ production and growth was studied but no significant improvement in either was observed, and the initial culture medium concentration of these salts was not modified.

The effect of the phosphate mixture $\left(\mathrm{K}_{2} \mathrm{HPO}_{4} / \mathrm{KH}_{2} \mathrm{PO}_{4}\right)$ was studied in the range of $1 / 0.5$ to $5 / 2.5$. As shown in Figure 2, when the phosphate concentration was increased from $1 / 0.5$ to $2 / 1$, a slight reduction in surface tension was observed as well as a considerable improvement in the buffering properties of the medium, which was maintained at $\mathrm{pH} 7$ during $18 \mathrm{~h}$ of culture. When $\mathrm{K}_{2} \mathrm{HPO}_{4} / \mathrm{KH}_{2} \mathrm{PO}_{4}$ was lowered, the supernatant rapidly acidified and bacterial growth stopped earlier.

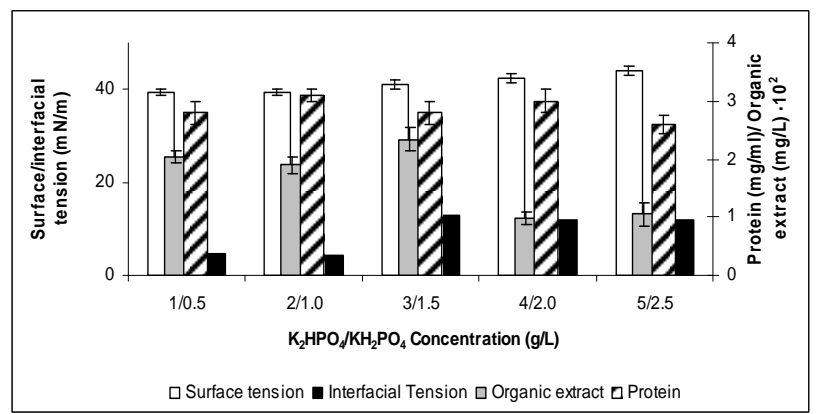

Figure 2: Effect of phosphate concentration on cellular growth and BS production after $48 \mathrm{~h}$ culture. Error bars indicate \pm standard deviation of three independent experiments.

In conclusion, the variables showing a positive effect on BS were carbon, nitrogen and phosphate sources. An MCA medium was developed based on these results.

\subsubsection{BS Production with different carbon sources}

The effect of different carbon sources on BS production was studied using MCA medium (2\% glucose) and $24-48 \mathrm{~h}$ of incubation. When glycerol was employed, growth was observed (Figure 3.A) but the surface tension did not drop below $40 \mathrm{mN} / \mathrm{m}$. When olive oil was used as an additional carbon source, abundant growth was observed (8.6 $\mathrm{mg}$ protein $/ \mathrm{mL}$ ) and surface tension was reduced to $40.0 \mathrm{mN} / \mathrm{m}$. Nevertheless, the control medium without an inoculum had a similar appearance and physicochemical properties, due to the oil emulsion formed by agitation. Additionally, no products were detected in the organic extract by TLC, which was severely hampered by residual olive oil. When kerosene and different $n$-alkane mixtures were used as the carbon source, satisfactory results were obtained in each case, with good surface tension reduction and amount of organic extract. Additionally, similar BS were detected by TLC. In 
conclusion, all the studied $n$-alkane mixtures could be used for BS production by $S$. detergens.

When the $\mathrm{C}_{11-13}$ concentration was optimized in the MCA medium, satisfactory results (interfacial tension and organic extract) were obtained with initial concentrations of 1.5 and $2 \%$, but $1.5 \%$ was chosen for posterior studies since an excess of $n$-alkane hampers organic extract manipulation and purification (Figure 3.B). Morita et al. [21] also consider that the use of vegetable oils and $n$-alkanes often complicates the production and recovery process and a difficult separation process is inevitable due to co-existing residual oils and their breakdown products. Better growth results (but not BS production) were obtained with $0.5 \% \mathrm{C}_{11-13}$, indicating partial toxicity to cells, especially at high concentrations.

Finally, the effect of the concentration of glucose with $1.5 \% \mathrm{C}_{11-13}$ was also studied (Figure 3.C). Bacterial growth and organic extract production were directly correlated with the glucose concentration and better results were obtained with $20 \mathrm{~g} / \mathrm{L}$ of glucose (p-value <0.05) Additionally, surface and interfacial tension decreased as the amount of organic extract increased $(37.1 \mathrm{mN} / \mathrm{m}$ and $6 \mathrm{mN} / \mathrm{m}$ respectively). As a result, MCA was prepared with $20 \mathrm{~g} / \mathrm{L}$ glucose.

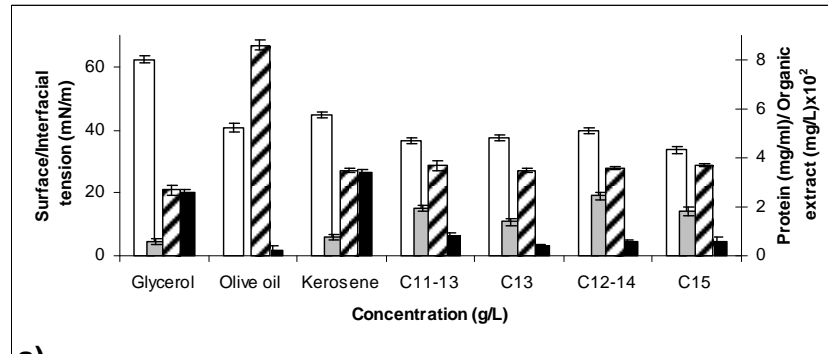

a)

$\square$ Surface Tension $\square$ Interfacial tension $\square$ Organic extract \Protein
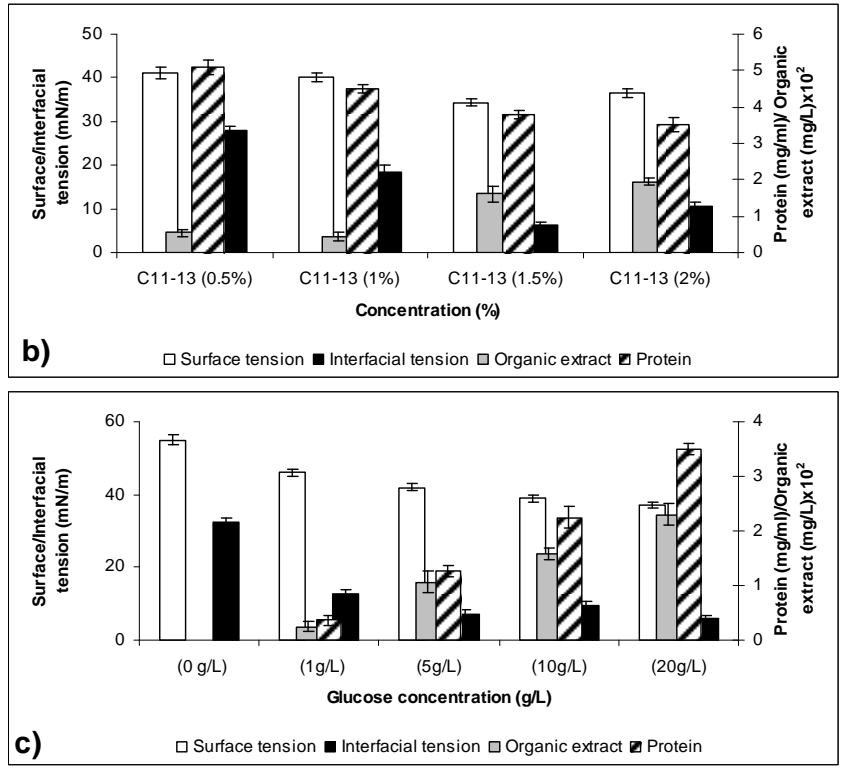

Figure 3: Effect of different carbon sources (a), $\mathrm{C}_{11-13}$ concentration (b) and glucose concentration (c) on growth, BS production and surface and interfacial tension after 24-48 culture. Error bars indicate \pm standard deviation of three independent experiments. 
The preferred carbon source for BS production depends on the identity of the producer microorganism. The majority of known BS are synthesized from water-immiscible hydrocarbons, although bacteria belonging to the Bacillaceae family, such as Bacillus subtilis strains, are able to produce surfactants from water-soluble substrates. Moreover, it has been reported that the addition of a hydrocarbon to the culture medium completely inhibits surfactin production by $B$. subtilis. Water-soluble substrates are cheaper than hydrocarbons and are preferred because single-phase cultivation is simpler than biphasic cultivation [11]. The known metabolic versatility of Pseumonads is also reflected in BS production, Among eleven carbon sources tested with $P$. aeruginosa MR01, the most favorable for BS production were olive oil, glycerol, glucose and fructose. The highest BS production of up to $1.4 \mathrm{~g} / \mathrm{L}$ and growth rate of $2.3 \mathrm{~g} / \mathrm{L}$ were achieved using $1 \%(\mathrm{v} / \mathrm{v})$ of olive oil as the sole carbon source [13]. Residual oils or by-products have also been described as very interesting, cheap carbon sources. $P$. aeruginosa 47T2 decreased the surface tension of the medium to $32-34 \mathrm{mN} / \mathrm{m}$ with a production yield of $0.34 \mathrm{~g} / \mathrm{g}$ when oils previously used for frying were employed as a unique carbon source [26]. However, in the case of $S$. detergens, although olive oil allows an abundant growth, it is not a good substrate for BS production.

\subsubsection{Time course of growth and BS production}

One of the primary approaches to increasing yields in culture production is medium improvement. Cell growth and the accumulation of metabolic products are strongly influenced by medium composition. Environmental factors and growth conditions or the method of extraction can also affect BS production by their impact on cellular growth [27]. Based on the results obtained using the classical one-factor-at-a-time strategy, the MCA medium was formulated with all the elements in the proportion that positively affected the BS production. The microbial growth kinetics and BS production in the MCA medium is presented in Figure 4. After a lag period of $6 \mathrm{~h}$, exponential growth (measured as protein concentration) began and was maintained until $30 \mathrm{~h}$. The maximum amount of cells was found to be $3.8 \mathrm{mg}$ protein $/ \mathrm{mL}$ after $30 \mathrm{~h}$ of incubation and was maintained during $54 \mathrm{~h}$ of growth. As exponential growth began, surface and interfacial tension decreased. The surface tension of the medium was reduced from 55 $\mathrm{mN} / \mathrm{m}$ to $35 \mathrm{mN} / \mathrm{m}$ after $24 \mathrm{~h}$ of growth, indicating BS production. Semi-quantitative TLC carried out with organic extracts obtained at different times revealed an increase in BS concentration until $30 \mathrm{~h}$, indicating that BS production was growth-associated. The initial low surface tension ( $\mathrm{T}=0$ ) was due to the presence of an excess of $\mathrm{C}_{11-13}$ in the MCA medium. Santa Anna et al. [10] similarly associated a low initial surface tension in the medium with babassu oil, due to the surfactant properties of the fatty acids in this vegetable oil. Glucose was consumed during exponential growth, but a residual concentration remained in the medium. Urea was consumed rapidly during the exponential growth and fully consumed after $30 \mathrm{~h}$, as shown in Figure 4 . Growth cessation was correlated with nitrogen consumption and medium acidification ( $\mathrm{pH} 5$ ). $\mathrm{C}_{11-13}$ consumption was measured by weight after medium extraction with hexane, but its insolubility impedes a precise determination. However, almost all the carbon source had disappeared from the supernatant by the end of the culture (48h). As mentioned before, biotransformations using oils as the carbon source are a challenge for culture control and active product extraction. The MCA medium enhanced the amount of organic extract available from $68 \mathrm{mg} / \mathrm{L}$ up to $250 \mathrm{mg} / \mathrm{L}$ compared with S-MSM, representing a 3.7-fold increase (Table 2). 


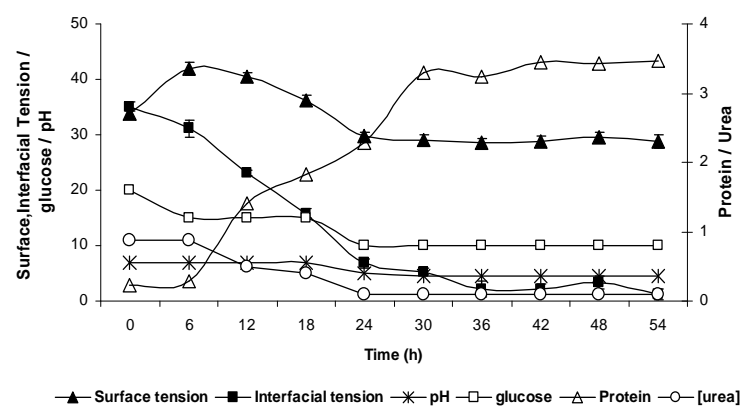

Figure 4: Time course profiles of protein $(\mathrm{mg} / \mathrm{ml})$, residual glucose $(\mathrm{mg} / \mathrm{L})$ and urea concentration $(\mathrm{mg} / \mathrm{L})$, surface and interfacial tension $(\mathrm{mN} / \mathrm{m})$ and $\mathrm{pH}$ during $S$. detergens growth in MCA medium. The points enclose the error bars ( \pm standard deviation) of three measurements.

Table 2: BS production, surfactant activity and growth in the different culture and extraction conditions studied. Results are expressed as mean \pm standard deviation of three experiments.

\begin{tabular}{cccccc}
\hline Culture medium & $\begin{array}{c}\text { Surface } \\
\text { tension } \\
(\mathrm{mN} / \mathrm{m})\end{array}$ & $\begin{array}{c}\text { Interfacial } \\
\text { tension } \\
(\mathrm{mN} / \mathrm{m})\end{array}$ & $\begin{array}{c}\text { Organic extract } \\
(\mathrm{mg} / \mathrm{L})\end{array}$ & $\begin{array}{c}\text { Protein } \\
(\mathrm{mg} / \mathrm{mL})\end{array}$ & $\begin{array}{c}\text { Relative } \\
\text { organic } \\
\text { extract } \\
\text { increase }\end{array}$ \\
\hline $\begin{array}{c}\text { S-MSM } \\
\text { MCA }\end{array}$ & $37 \pm 1.0$ & $10 \pm 0.9$ & $68 \pm 3.2$ & $0.57 \pm 0.02$ & 1 \\
$\begin{array}{c}\text { MCA + } \\
\text { Lyophilization }\end{array}$ & $36 \pm 1.0$ & $6 \pm 0.6$ & $250 \pm 6.2$ & $3.8 \pm 0.4$ & 3.7 \\
$\begin{array}{c}\text { MCA + feed + } \\
\text { lyophilization }\end{array}$ & $36.5 \pm 1.0$ & $5 \pm 0.7$ & $466 \pm 6.9$ & $4.7 \pm 0.5$ & 6.9 \\
\hline
\end{tabular}

During the exponential growth phase, the $\mathrm{pH}$ dropped markedly from 7 to 4.5 after 24 hours of culture, and consequently cell growth stopped and BS production did not increase. $\mathrm{pH}$ control of the medium is therefore necessary for optimal BS production and cell survival.

Depending on the producing microorganisms, several patterns of biosurfactant production by fermentation are possible [27]. Surfactant biosynthesis on cassava waste started during the exponential growth phase and continued during the stationary phase, although it cannot be stated that BS production by B. subtilis is growth-associated, since $50 \%$ of it occurred when cell growth reached the stationary phase [11]. BS production by many microorganisms is associated with the stationary phase, including ramnolipid production by $P$. aeruginosa PA1, which increased considerably in this phase [10]. Growth curves of Saccharomyces cerevisiae and Candida albicans on diesel-oil were obtained to establish the relation between cell growth and BS production. Growth peaked at day 8, while BS was detected at day 2, when growth was almost inexistent, with maximal production obtained during the stationary/death phase of growth, suggesting that BS were produced as secondary metabolites [8]. With P. aeruginosa MR01, maximum BS production occurred in the stationary growth phase (after $84 \mathrm{~h}$ ). The bacterial growth was fast at $37^{\circ} \mathrm{C}$ and a final dried cell mass of about $1.65 \mathrm{~g} / \mathrm{L}$ was obtained after $84 \mathrm{~h}$ of cultivation resulting in a BS production of up to $0.8 \mathrm{~g} / \mathrm{L}$ [13]. With $P$. aeruginosa $\mathrm{D}$ and using coconut oil, a diauxic profile for surfactant accumulation was observed. The rhamnolipid production started after $24 \mathrm{~h}$ of incubation and was completed in two stages [28]. Azotobacter chroococum cultured on peanut oil 
cake in both flask and bioreactor conditions gave a higher BS production than on crude oil and waste motor lubricant oil, indicating that this cheaper substrate is suitable for large-scale BS production. In all culture conditions tested, BS concentration was highest in the early stationary phase [29]. Similarly to $S$. detergens, the marine $B$. circulans (MTCC 8281) displayed BS production in a growth-associated manner [9] and the BS production by L. lactis 53 and Streptococcus thermophilus $A$ was found to be growthassociated [27].

\subsubsection{Optimization of BS extraction}

The production process remains incomplete without an efficient and economical means of product recovery. For many biotechnological products, downstream processing accounts for $\sim 60 \%$ of the total production costs $[4,21]$. The organic solvent and the extraction technique can also modify the yield, cost and type of compounds extracted. Thus, different organic solvents were studied in the same conditions. Methyl tertiary butyl-ether is recommended for BS extractions by Kuyukina et al. [30] due to its low toxicity and cost, but this organic solvent resulted in an insufficient amount of organic extract (40.6 mg/L) (Figure 1 suppl.). More organic extract was obtained with ethyl acetate $(153.1 \mathrm{mg} / \mathrm{L})$, but verification of its components by TLC showed that product diversity and the amount extracted $(220 \mathrm{mg} / \mathrm{L})$ was higher with ethyl acetate/methanol (8:1) (Figure 1 suppl.). Chloroform is a hydrophobic solvent frequently used in extractions, but it was not effective for organic extraction with $S$. detergens culture $(18.1 \mathrm{mg} / \mathrm{L})$. Hexane, the most non-polar organic solvent, showed a good affinity for the carbon source $\left(\mathrm{C}_{11-13}\right)$ but only a small quantity of products was detected by TLC. In this case, the organic extract obtained was liquid due to the extraction of both the $n$ alkane and BS, and so was not quantified by weight. In fact, Daverey and Pakshirajan [23] used hexane to remove remaining oil and any hydrophobic substances such as fatty acids and alcohols that may be formed during fermentation in the sophorolipid production process. If not previously removed, a residual lipidic carbon source can be co-extracted and cause difficulties during further applications. For this reason, additional extraction with hexane is most frequently used.

Even after optimization of culture and organic extraction, procedural efficiency can be further increased if the product is concentrated prior to extraction. To improve recovery, the culture supernatant of $S$. detergens was lyophilized and extracted three times with ethyl acetate/methanol (8:1). $400 \mathrm{mg} / \mathrm{L}$ of organic extract was obtained, which was 5.9fold higher than the initial extraction (Table 2).

The low concentration and the amphiphilic nature of microbial surfactants often limit their recovery. A wide variety of organic solvents have been used for BS extraction, either singly or in combination. Chloroform and methanol mixtures in various ratios are usually the most effective, facilitating the adjustment of polarity of the extraction agent to the target extractable material. However, the use of chloroform is not economically warranted and is a highly toxic chloro-organic compound regarded as harmful for the environment and human health [30]. With S. detergens the best results (amount and number of products) were obtained after extraction with ethyl acetate and methanol $(8: 1)$, which are also recommended for their lower toxicity.

\subsubsection{Feed-batch culture}


The cell viability evolution of $S$. detergens strain $6.2 \mathrm{~S}$ was studied by the observation of ultrathin sections at 0,24 and $48 \mathrm{~h}$ of growth. Strain $6.2 \mathrm{~S}$ has a characteristic gramnegative envelope and structure (TSA) (Figure 5a). After 24 hours, an altered cytoplasm (Figure 5b) with clear zones was observed, indicating a possible $\mathrm{C}_{11-13}$ intracellular accumulation and a high amount of extracellular material. After $48 \mathrm{~h}$ (Figure 5c), the cytoplasm was condensed and the bacterial wall was disrupted suggesting a high proportion of non viable cells (Figure 5c).
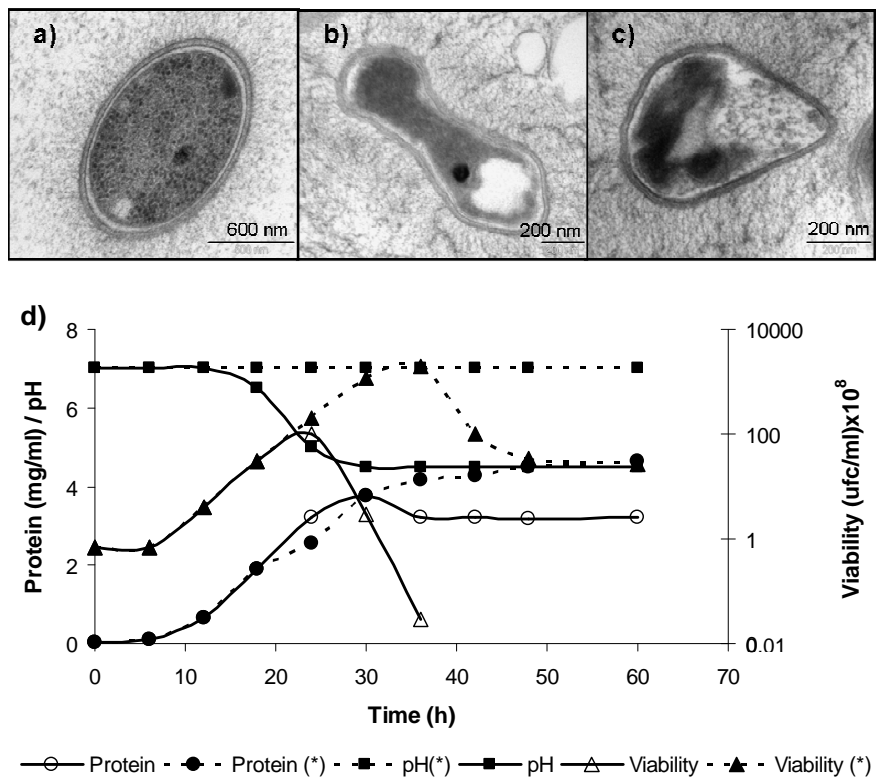

Figure 5: ME photomicrographs of $S$. detergens control in TSA (a) and after 24 (b) and $48 \mathrm{~h}$ (c) growth in MCA medium. Biomass and cell viability in batch $(-)$ and feed-batch cultures (.....) (d).

To confirm this observation a cell viability study by colony plate count was carried out with fed-batch and batch cultures (Figure 5d). As described previously (Figure 4), exponential growth continued until $30 \mathrm{~h}$, but a marked decrease in viability was observed after $24 \mathrm{~h}$ of growth, associated with a marked decrease in medium $\mathrm{pH}$ from 7 to 5 . In the fed-batch culture, urea was added $(0.88 \mathrm{~g} / \mathrm{L})$ after 24 and $48 \mathrm{~h}$, and the acidic $\mathrm{pH}$ was neutralized to 7 with $1 \mathrm{~N} \mathrm{NaOH}$. As a result, exponential growth continued until $60 \mathrm{~h}$ and only a small decrease in viability was observed after $42 \mathrm{~h}$ of culture. Consequently, the time for exponential growth and BS production was longer, resulting in $4.7 \mathrm{mg} / \mathrm{mL}$ biomass and $466 \mathrm{mg} / \mathrm{L}$ of organic extract (obtained with prior supernatant lyophilization). When a fed-batch culture was used, organic extract production increased from 400 to $466 \mathrm{mg} / \mathrm{L}$, respresenting a 6.9 -fold increase with respect to the initial production with S-MSM medium (Table 2).

BS compete with surfactants of petrochemical origin in three aspects: cost, functionality, and production capacity to meet the needs of the intended application [31]. Any attempt to increase BS yields requires an optimal addition of media components and selection of the optimal culture conditions to induce the maximum productivity [4]. However, in the cosmetic or pharmaceutical sectors, higher price dimensions are standard, and therefore, BS can easily compete. 


\subsubsection{Organic extract solubility}

Solubility was studied with the most frequently used organic solvents. Organic extracts were dissolved with some difficulty in water and ethyl acetate, sonication being necessary to obtain a brown translucent dispersion. In contrast, they were rapidly dissolved with methanol or ethanol, while being only partially soluble in chloroform and $n$-hexane, resulting in a cloudy dispersion. There was almost no solubility in acetonitrile.

The water solubility of the surfactant can be used to obtain a rough approximation of its HLB value [32]. When a complete organic extract was dissolved in water a translucent dispersion was obtained corresponding to an HLB of 11-13. TLC of the complete organic extract revealed many compounds. After extract purification, two fractions, apolar (A) and polar (P), were obtained. Fraction A was highly apolar and consisted of a phospholipid mixture, phosphatidylethanolamine being the most abundant compound [14]. Upon dissolving, a milky dispersion was obtained after vigorous agitation, and it corresponded to an HLB of 8-6. Fraction P, a more polar nitrogenated lipid, also consisted of a mixture of BS. This fraction dissolved easily in water giving a transparent brown solution, which corresponded to an HLB of 14-20 [33]. Fraction P was initially characterized as a lipopeptide but the absence of amino acid components in its acid digestion led us to discard this possibility. The presence of nitrogen in its polar head, its physicochemical properties and possible molecular weight, and the taxonomic position of the producer bacteria suggest that this compound could form part of the Flavolipid family of the Siderophore group [34].

In summary, a modified mineral MCA medium has been developed, containing urea and two carbon sources for the co-metabolic BS production by $S$. detergens. Additionally, the growth strategy was modified with 24 and $48 \mathrm{~h}$ fed-batch cultures and BS extraction was optimized. These changes induced a 6.9 -fold increase in production (Table 2).

\subsection{Physicochemical characterization}

Solutions and dispersions of the complete fraction and purified fractions $\mathrm{A}$ and $\mathrm{P}$ were studied in more detail. The samples were prepared by weighing the powder and adding water to the initial concentration. The samples were then vortexed and sonicated at room temperature. Dilutions were made from these stock solutions by adding water or the appropriate aqueous solutions. The aggregates formed were characterized by determining their hydrodynamic radii and z-potential. Concentrated solutions were also examined by X-Ray scattering to gain a deeper understanding of the structure of the aggregates. Finally, adsorption from solution was also examined as a function of $\mathrm{pH}$.

\subsubsection{Hydrodynamic radii and $\zeta$-potential.}

Concerning the $\zeta$-potential results, no dependence was apparent for the different samples as a function of concentration (results not shown). All values fell within $-57 \pm 9$ $\mathrm{mV}$, which corresponds to electrostatically stabilized particles [33]. On the contrary, the 
size of the particles was independent of concentration only for the polar fraction and the complete fraction below $10 \mathrm{~g} / \mathrm{L}$ (Figure 6). The dispersions of the apolar fraction were too turbid to be measured at concentrations above $0.1 \mathrm{~g} / \mathrm{L}$ and the decrease in radius was only apparent and caused by the excess of dispersion. One would expect the size to be independent of concentration for kinetically stable vesicles [35], which could be the case of the polar and complete fraction and the apolar fraction below $0.01 \mathrm{~g} / \mathrm{L}$. The low concentration at which samples from the apolar fraction still produced a reasonable scattered intensity for measurement was somewhat surprising, particularly if we compare this to the critical micellization concentration CMC obtained from the stabilization of the solution surface tension: 0.2 to $0.001 \mathrm{~g} / \mathrm{L}$. This could mean that the molecules responsible for the decrease of the surface tension and the objects measured by light dispersion may be different. This problem should be resolved by the ongoing identification and further purification of the active surfactant species in these mixtures.

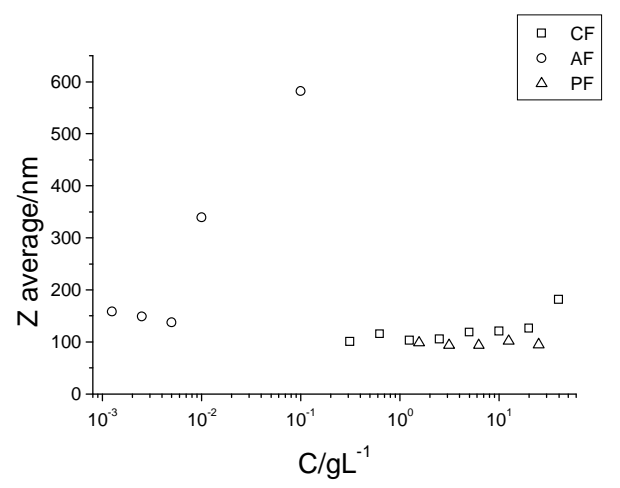

Figure 6: $\mathrm{Z}$ average as a function of concentration for the three fractions studied. The measurements were performed at $25^{\circ} \mathrm{C}$ (complete fraction $\square$; apolar fraction $\circ$; polar fraction $\Delta$ ).

The negative $\zeta$-potential agrees with the observation of titrable protons with a pKa of 5.2 [14]. Titration of the samples with acid did show neutralization of the $\zeta$-potential (Figure 7a) and systematic increases in size (Figure $7 b$ ). The increase in size occurs close to the point where the $\zeta$-potential decreases in absolute value below $20 \mathrm{mV}$, agreeing with the classical view of electrostatic stabilization. Therefore, the growth can be attributed to flocculation of smaller entities.

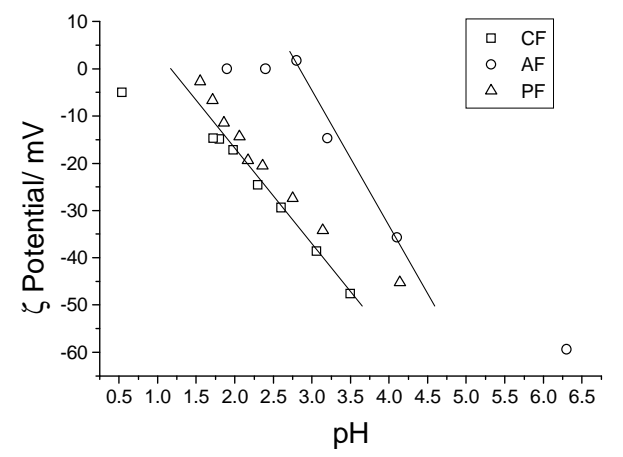




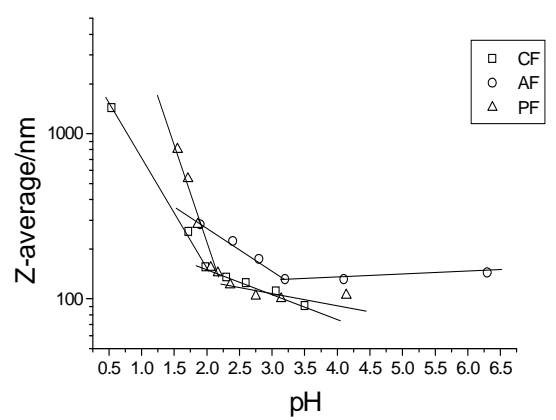

Figure 7: a) $\zeta$-potential as a function of $\mathrm{pH}$ for the three fractions studied. The measurements were performed at $25^{\circ} \mathrm{C}$. Initial sample concentration was $5 \mathrm{~g} / \mathrm{L}$ for the complete fraction, $0.005 \mathrm{~g} / \mathrm{L}$ for the apolar fraction and $1.6 \mathrm{~g} / \mathrm{L}$ for the polar fraction (complete fraction $\square$; apolar fraction $\circ$; polar fraction $\Delta$ ). b) $\mathrm{Z}$ average as a function of $\mathrm{pH}$ for the three fractions studied. The measurements were performed at $25^{\circ} \mathrm{C}$. The concentrations are as in Figure 7 (Complete fraction $\square$; apolar fraction $\circ$; polar fraction $\Delta$ ).

A significant difference between the different fractions is the $\mathrm{pH}$ at which neutralization and growth occur. While the apolar fraction lost most of its charge at $\mathrm{pH}=3$, the other two fractions maintained a significant proportion up to $\mathrm{pH}=2$. This is unexpected, considering we obtained a $\mathrm{pKa}$ value of 5.2 from the titration, which would imply that the Z-potential did not decrease until the proportion of charged groups was below $1 \%$ and $0.1 \%$, respectively. A possible explanation for this observation could come from a difference in the measured $\mathrm{pKa}$ and the intrinsic $\mathrm{pKa}$ of the charged groups, that is, a $\mathrm{pKa}$ shift due to aggregation. It is tempting to attribute the $\mathrm{pKa}$ value observed from titration to the presence of carboxylic acid groups. However, the $\zeta$-potential titration suggests groups with an intrinsic $\mathrm{pKa}$ of 1-3, a reasonable candidate being phosphate or citrate. Indeed, strong $\mathrm{pKa}$ shifts have been observed for different phospholipids, either zwiterionic or with a net charge [35-37]. The remaining difference between the intrinsic pKa of the apolar fraction and the other two fractions could be due to either a real difference between the polar heads or to remaining differences in aggregation between single and double chain phosphates.

\subsubsection{Small-angle X-ray scattering and polarized microscopy}

More details about the aggregation were obtained from polarizing light microscopy and small angle x-ray scattering. The complete and apolar fractions showed similar results with both techniques. The polarizing optical microscopy revealed the formation of threaded structures and Maltese crosses, both characteristic of lamellar liquid crystalline phases [38] (Figure 8). The SAXS results were also compatible with bilayer structures. 


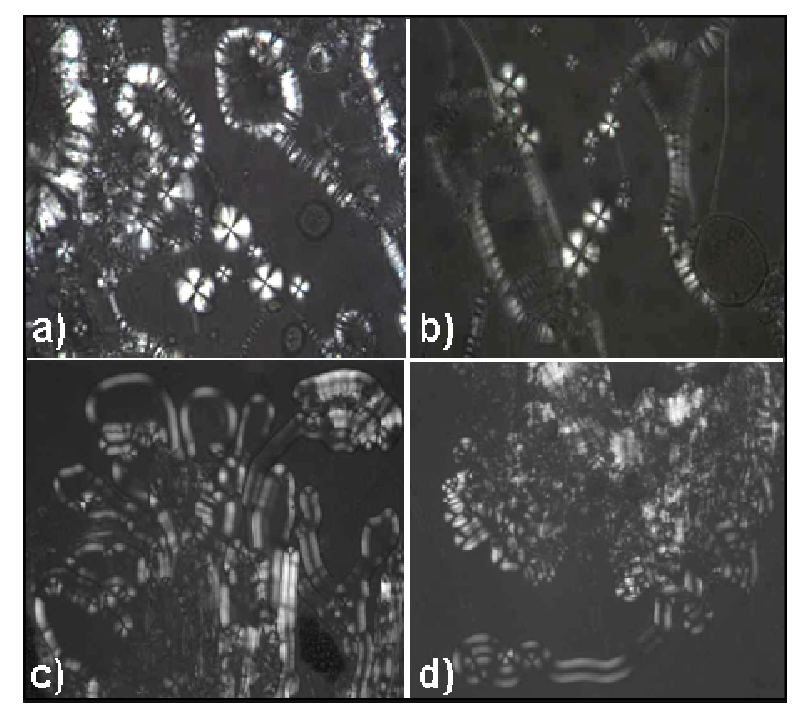

Figure 8: Crossed polarizing optical microscopy of water penetrated samples at $25^{\circ} \mathrm{C}$. Upper images (a,b) correspond to the complete fraction with 848 while lower images $(\mathrm{c}, \mathrm{d})$ correspond to the apolar fraction. The width of the pictures corresponds to 848 ( a,b) and $212 \mu \mathrm{m}$ (c,d).

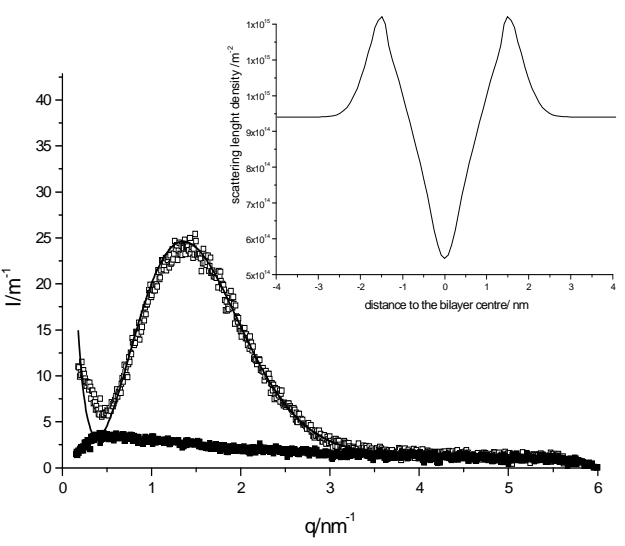

Figure 9: $\mathrm{X}$-ray scattering intensity as a function of dispersion vector modulus $\mathrm{q}$ measured at $25^{\circ} \mathrm{C}$. The concentration of the apolar fraction (open symbols) was $10 \mathrm{~g} / \mathrm{L}$ and that of the polar fraction $4 \mathrm{~g} / \mathrm{L}$ (full symbols). For the apolar fraction the curve corresponds to the MCG model fitting and the insert corresponds to the scattering length density across the bilayer for this model.

Figure 9 shows the intensity obtained as a function of the dispersion vector at $25^{\circ} \mathrm{C}$, together with the fit of a bilayer model for the apolar fraction (see the experimental section for details of the fitted model) $[18,19]$. In the inset the scattering length density as a function of the distance from the center of the bilayer is also shown. The scattering length density of hydrocarbon is lower than that of water while that of the polar groups is typically higher. The hydrophobic core of the bilayer has a thickness of $1.5 \mathrm{~nm}$, which could correspond to interdigitated hydrocarbon chains with 14-18 carbon atoms. Increasing the temperature to $37^{\circ} \mathrm{C}$ did not result in any significant differences in scattering intensity and bilayer thickness, which was $5.0 \mathrm{~nm}$. This bilayer was thicker than those obtained from dirhamnolipids [6] and comparable to those obtained from classic phospholipids. The electronic profile, however, shows a more extended polar 
head region than that of classic phospholipids [18], possibly due to the presence of large polar groups. On the other hand, interdigitation is thought to contribute to pore formation in phospholipid bilayers and consequently to the hemolytic and bactericidal activity of surfactants [39].

The polar fraction did not show any significant textures when observed by polarizing light microscopy, except in the dry state when crystals were formed at room temperature. The SAXS measurements were significantly different from those of the other two fractions. The intensity was considerably lower and appreciable scattering was only observed at small q. The fitting of globular models did not lead to any significantly good fitting for any set of reasonable parameters. The low intensity itself may be partly the result of the higher CMC and also due to partial cancellation of intensity from above and below water electron densities. No further details could be elucidated for this sample due to this low intensity and high noise of the SAXS.

While a difference in $\zeta$-potential behavior as a function of $\mathrm{pH}$ was observed between the apolar fraction and the other two fractions, in the more concentrated regime observed by PLM and SAXS the different behavior corresponded to the polar fraction. This must be a consequence of the different techniques sensing different properties and the different fractions containing varying proportions of some of the active molecules. While the most soluble part of the complete fraction provides a $\zeta$-potential that can be brought to zero only at $\mathrm{pH}=1.2$, the less soluble is already cancelled at $\mathrm{pH}=2.9$. This can be explained by considering that the more soluble components are single chain compounds while the less soluble are double chain compounds. The double chain components induce the formation of vesicles and lamellar liquid crystalline phases, which were detected both in the complete and apolar fractions. The pKa shift induced by aggregation may be stronger for a flatter structure like those formed in the apolar and complete fractions, compared to the smaller structures formed by the polar fraction.

\subsubsection{Surface tension characterization}

To further characterize the physicochemical behavior of the complete fraction, the surface tension of solutions at different $\mathrm{pH}$ were measured as a function of concentration. The results are plotted in Figure 10. Three $\mathrm{pH}$ conditions were studied: buffering at $\mathrm{pH}=3$ (below the titration $\mathrm{pKa}=5.2$ ), $\mathrm{pH}=7$ (above the titration $\mathrm{pKa}$ ) and at the natural $\mathrm{pH}$ of the solutions ( $\mathrm{pH}$ ranging from $\sim 6$ at low concentration to 3.5 at high concentration). 


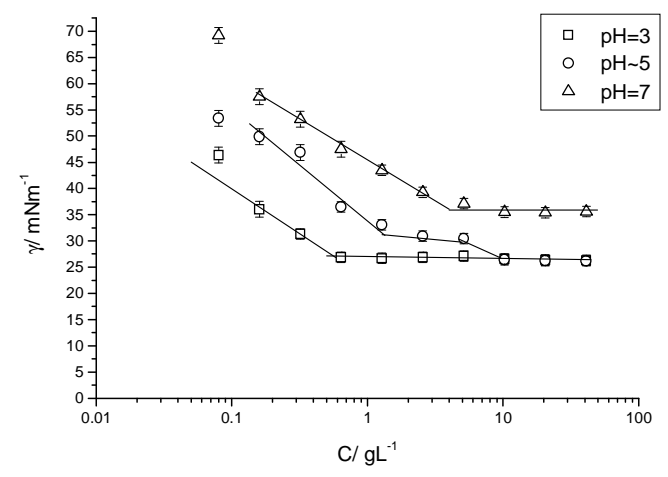

Figure 10: Surface tension as a function of surfactant concentration measured at $25^{\circ} \mathrm{C}$ and three $\mathrm{pH}$ conditions by means of the ring method for the complete fraction. Error bars indicate \pm standard deviation.

The higher the $\mathrm{pH}$, the higher the concentration at which the surface tension stabilizes. This observation is consistent with the polar heads of the surfactant being $\mathrm{pH}$-sensitive, with the negative charge of the acid groups increasing along with the $\mathrm{pH}$. The higher the charge the higher the solubility of the monomer and, therefore, the higher the concentration at which the surface tension stabilizes, presumably due to the formation of micelles or vesicles [32]. The disappearance of the intermediate plateau at $\mathrm{pH}=7$ and $\mathrm{pH}=3$ deserves further comment. Our group previously attributed this intermediate plateau to the presence of some protein on which micellization took place before reaching the water monomer solubility [14]. These differences can be understood on the basis of the different charge behavior of the surfactant molecules and protein. At neutral $\mathrm{pH}$ the surfactant molecules were mainly negatively charged, their aqueous solubility had increased and, at the same time, the affinity for the protein had decreased. The decreased affinity can be due to the increased global negative charge of the protein, which would account for a net repulsion of the surfactant to the protein. At acidic $\mathrm{pH}$ the protein charge should turn more positive but the main effect would be a decreased solubility of the monomer and a consequent decrease of the critical aggregation concentration to forming vesicles. Even if some aggregation occurs on the protein, the effect can no longer be detected because the protein-surfactant aggregates would be less surface-active than the surfactant aggregates. The observed behaviour contrasted with that of surfactin, which, precipitates at a $\mathrm{pH}$ below 5 and becomes much less surface active. Some authors have attributed the precipitation to the presence of protein impurities in their samples [40]. However, the possible precipitation of proteinaceous material should not affect the surface tension behaviour except in two particular cases; that is, if the proteinaceous material itself is surface active or if the surfactant has a special affinity for adsorbing to the precipitate. 


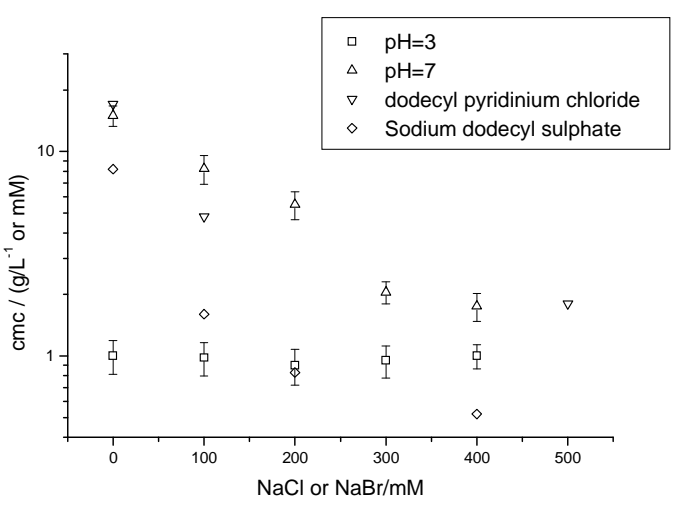

Figure 11: Effect of $\mathrm{NaCl}$ addition on the surface tension $\mathrm{cmc}$ at neutral (up triangles) and acidic conditions (squares) measured at $25^{\circ} \mathrm{C}$. The $\mathrm{CMC}$ of dodecyl pyridinium chloride (drown trinagles) and sodium dodecyl sulfate (diamonds) from the literature [32] as a function of $\mathrm{NaCl}$ concentration at $25^{\circ} \mathrm{C}$ are also shown for comparison. The $\mathrm{CMC}$ values are given in $\mathrm{g} / \mathrm{L}$ in the case of the biosurfactants and $\mathrm{mM}$ in the case of the literature values. Error bars indicate \pm standard deviation.

The effect of ionic strength on the $\mathrm{CMC}$ at $\mathrm{pH}=3$ and $\mathrm{pH}=7$ is reasonable for nonionic molecules in the first case and ionic molecules in the second. The CMC at low $\mathrm{pH}$ is independent of ionic strength (n.b. we can only compare within a limited range of ionic strength because the initial point for acquiring the desired $\mathrm{pH}$ already has a significant ionic strength). In the case of neutral $\mathrm{pH}$, the ionic strength has a significant decreasing effect on the CMC, as found in ionic surfactants [32]. In Figure 11 we compare the influence of ionic strength on the BS CMC at two $\mathrm{pH}$ values with the data of an anionic and cationic surfactant from the literature. These observations agree with the general behavior exposed above concerning the different charging situations at different $\mathrm{pH}$.

\section{CONCLUSIONS}

Successful biosurfactant commercialization partly depends on bioprocess economics and knowledge of BS properties [11]. In the present study, surfactant production by the new BS producer, $S$. detergens, has been improved by a systematic one-factor-at-a-time screening approach focusing on medium composition, carbon feeding strategy/pH control and downstream processing. The developed MCA medium contained urea and glucose plus $\mathrm{C}_{11-13}$ to allow the co-metabolism requisite for bacterial BS production. The use of two different carbon sources for BS production is not frequent [22-25], but in the present case it seemed to be essential. The use of glucose alone led to bacterial growth but without BS production, while no bacterial growth was observed when only n-alkane was added to the media. The results obtained with this medium showed that BS production is growth-associated. Medium optimization resulted in a 3.6-fold increase in the organic extract production. The downstream optimization and feed strategy are also important in the process economy, leading to an 1.8-fold increase in production. The overall increase in BS production was 6.9-fold.

The different fractions obtained by purification of the crude extract behaved differently according to their polarity. All fractions produced negatively charged particles that lost their charge upon acidification, with proton affinities compatible with phosphate as one of the components of the head-group. The complete extract and polar fraction showed similar behavior, while the apolar fraction was neutralized at a higher $\mathrm{pH}$. Upon charge 
neutralization, all fractions showed particle growth, probably by flocculation induced by the absence of charge stabilization. The complete extract and the apolar fraction formed lamellar phases with a bilayer thickness of around $5.0 \mathrm{~nm}$, about $1.5 \mathrm{~nm}$ being occupied by the hydrophobic moieties. This suggests the presence of large polar heads and interdigitation of the hydrophobic moieties [18]. The low scattering signal obtained from the polar fraction must be related with high monomer solubility combined with low aggregate contrast. In contrast with the electrokinetic studies, SAXS showed a similarity in behavior of the complete extract and the apolar fraction. The surface tension at controlled $\mathrm{pH}$ can be interpreted in terms of headgroup charge changes due to the presence of weak acid protons producing predominantly charged species at neutral $\mathrm{pH}$ and species with no net charge at acidic $\mathrm{pH}$.

The promising BS production yields shown by $S$. detergens $6.2 \mathrm{~S}$, together with the high efficacy of this BS mixture in reducing surface tension, make it a good candidate for industrial development as an environmentally acceptable BS.

\section{Acknowledgements:}

We are grateful to J. Caelles of the SAXS-WAXS service at IQAC for technical assistance with SAXS measurements. I. Carrera is acknowledged for experimental help with the physicochemical characterization. Financial support from the Spanish Ministry of Economy and Competitiveness through projects CTQ2007-66244 and CTQ201014897 and Generalitat de Catalunya though Grant 2009SGR1331 is gratefully acknowledged.

\section{References}

[1] J.D. Van Hamme, A. Singh, O.P. Ward, Biotechnol. Adv. 24 (2006) 604.

[2] I.D. Bushnell, H.E. Hass, J. Bacteriol. 41 (1941) 653.

[3] M. Pacwa-plociniczak, G.A. Plaza, Z. Piotrowska-Seget, S.S. Cameotra Int. J. Mol. Sci. 12, (2011) 633.

[4] S. Mukherjee , P. Das , R. Sen Trends Biotechnol. 24 (2006) 509.

[5] A. Pinazo, M. Angelet, R. Pons , M. Lozano , M.R. Infante , L. Pérez L. Langmuir 25 (2009) 7803.

[6] M. Sánchez , F.J. Aranda , M.J. Espuny, A. Marques , J.A. Teruel J.A., A. Manresa

, A. Ortiz J. Colloid Interface Sci. 307 (2007) 246.

[7] S. Joshi, S. Yadav, A. Nerurkar, A.J. Desai J. Microbiol. Biotechnol. 17 (2007) 313.

[8] M.O. Ilori, S.A. Adebusoye, A.C. Ojo World J. Microbiol. Biotechnol. 24 (2008) 
[19] C. Sivapathasekaran, S. Mukhrjee, R. Sen. Biotechnol. J. 5 (2010) 1060.

[10] L.M. San Anna, G.V. Sebastian, E.P. Menezes, T.L.M. Alves, A.S. Santos, N. Pereira Jr., D.M.G. Freire, Brazilian J. Chem Engin. 19 (2002) 159.

[11] M. Nitscke, G.M. Pastore, Bioresour. Tecnol. 97 (2006) 336.

[12] S. Mukherjee, P. Das, C. Sivapathasekaran, R. Sen, Biochem. Eng. J. 42 (2008) 245.

[13] T.B. Lotfabad, M. Shourian, R. Roostaazad, A.R. Najafabadi, M.R. Adelzadeh, K.A. Noghabi, Colloids Surface B Biointerfaces 69 (2009) 183.

[14] C. Burgos-Díaz, R. Pons, M.J. Espuny, F.J. Aranda, J.A. Teruel, A. Manresa, A. Ortiz, A.M. Marqués, J. Colloid Interface Sci. 361 (2011) 195.

[15] A.M. Marqués, C. Burgos-Díaz, F.J. Aranda, J.A. Teruel, A. Manresa, A. Ortiz, M. Farfan, Inter. J. Syst. Evol. Microbiol. doi: 10.1099/ijs.0.036707-0 (2012).

[16] D. Orthaber, A. Bergmann, O. Glatter, J. Appl. Cryst. 33 (2000) 218.

[17] L. Pérez, A. Pinazo, M.R. Infante, R. Pons, J. Phys. Chem. B 111 (2007) 11379.

[18] G. Pabst, M. Rappolt, H. Amenitsch, P. Laggner, Phys. Rev. E 62 (2000) 4000.

[19] M.C. Morán, A. Pinazo, P. Clapés, M.R. Infante, R. Pons, J. Phys. Chem. B 109 (2005) 22899.

[20] R.G. Laughlin, The Aqueous Phase Behavior of Surfactants, Academic Press, London, 1994.

[21] T. Morita, T. Fukuoka, T. Imura, N. Hirose, D. Kitamoto, Biosci. Biotechnol. Biochem. 76 (2012) 1788.

[22] I.N.A.Van Bogaert, K. Saerens, C. De Muynck, D. Develter, W. Soetaert, E.J. Vandamme, Appl. Microbiol. Biotechnol. 76 (2007) 23.

[23] A. Daverey, K. Pakshirajan, Food Res. Int. 42 (2009) 499. 
[24] S. Pansiripat, O. Pornsunthorntawee, R. Rujiravanit, B. Kitiyanan, P. Somboonthanate, S. Chavadej, Biochem. Engin. J. 49 (2010) 185.

[25] F.M. Bento, C.C. Gaylarde, Int. Biodeter. Biodegrad. 38 (1996) 31.

[26] E. Haba, M.J. Espuny, M. Busquets, A. Manresa, J. Appl. Microbiol. 88 (2000) 379.

[27] L. Rodrigues, J. Teixeira, R. Oliveira, H.C. van der Mei, Process Biochem. 41 (2006) 1.

[28] G. Seba, K. Jayachandran, J. Appl. Microbiol. doi:10.1111/Jam.12069 (2012).

[29] R. Thavasi, V.R.M. Subramanyam Nambaru, S. Jayalakshmi, T. Balasubramanian , I.M. Banat, Mar Biotechnol. 11 (2009) 551.

[30] M.S. Kuyukina, I.B. Ivshina, J.C. Philp, N. Christofi, S.A. Dunbar, M.I. Ritchkova, J. Clin. Method. 46 (2001) 149.

[31] J.M Luna, R.D. Rufino, C.D.C. Alburquerque, L.A. Sarubbo, G-M CamposTakaki, Int. J. Mol. Sci. 12 (2011) 2463.

[32] M.J. Rosen, Surfactants and Interfacial Phenomena. John Wiley, New Jersey, USA (2004).

[33] W.A. Adamson, in: Physical Chemistry of Surfaces 5th edition, p.218. John Wiley and Sons, New York, 1990.

[34] G. Soberón-Chávez, R.M. Maier, in: G. Soberón-Chavez (Ed.), Springer-Verlag, Berlin, 2011, p.1.

[35] N. Lozano, A. Pinazo, C. La Mesa, L. Pérez, P. Andreozzi, R. Pons, J. Physical Chem. B 113 (2009) 6321.

[36] E.E. Kooijman, K.M. Carter, E.G. van Laar, V. Chupin, K.N.J. Burger, B. de Kruijff, Biochem. 44 (2005) 17007.

[37] M.R. Moncelli, L. Becucci, R. Guidelli. Biophys. J. 66 (1994) 1969. 
[38] F.B. Rosevear, J. Soc. Cosmetic Chemists, 19 (1968)581.

[39] T-S. Nguyen, P.M.M. Weers, V. Raussens, Z. Wang, G. Ren, T. Sulchek, P.D. Hoeprich Jr., R.O. Ryan, BBA-Biomembranes 1778 (2008) 303.

[40] D. Altmajer Vaz, E. J. Gudiña, E.Jurado Alameda, J.A. Teixeira, L.R. Rodrigues, Colloids Surface B Biointerfaces 89 (2012) 167. 
Figure 1 supplementary

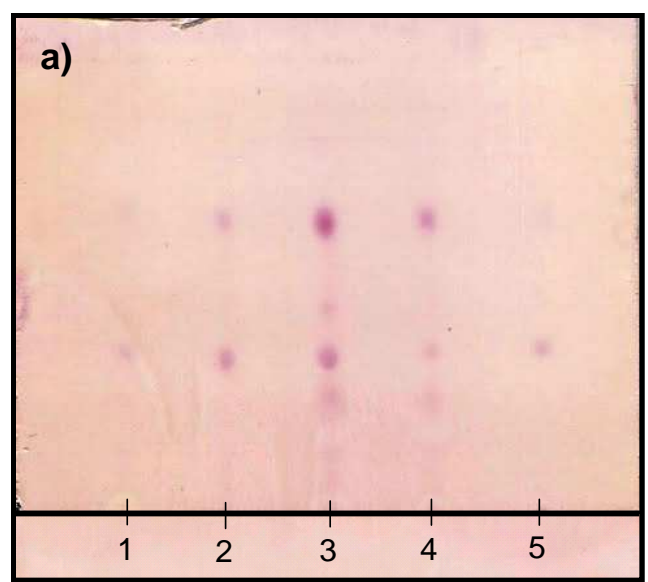

\begin{tabular}{lc}
\hline b) Organic solvent & $\begin{array}{c}\text { Extract weight } \\
(\mathrm{mg} / \mathrm{L})\end{array}$ \\
\hline 1 Methyl tertiary- butyl ether & $40.6 \pm 3.1$ \\
2 Chloroform & $18.1 \pm 1.5$ \\
3 Ethyl acetate/methanol (8:1) & $220 \pm 7.6$ \\
4 Ethyl acetate & $153.1 \pm 3.8$ \\
5 Hexane & Not quantified \\
Lyophilization + Ethyl & $400 \pm 7.0$ \\
acetate/methanol (8:1) & \\
\hline
\end{tabular}

